\title{
REÚSO DE ÁGUA A PARTIR DE EFLUENTES DE ESTAÇÕES DE TRATAMENTO DE ESGOTOS PARA IRRIGAÇÃO DE PASTAGENS NA BACIA HIDROGRÁFICA DO RIO MEIA PONTE
}

\section{WATER REUSE FROM EFFLUENTS OF SEWAGE TREATMENT STATIONS FOR PASTURE IRRIGATION IN THE HYDROGRAPHIC BASIN OF RIO MEIA PONTE}

\author{
Karla Alcione da Silva Cruvinela, Hadrya Alves Maciel a, Lhais Alves Maciel a, \\ Klaem José da Silva Junior a ${ }^{\text {, Ricardo Franci Gonçalves }}{ }^{b}$ \\ aUniversidade Federal de Goiás, ${ }^{b}$ Universidade Federal do Espírito Santo \\ karlaalcione@ufg.br, hadryaalves@gmail.com, lhaisalvesmaciel@hotmail.com, \\ klaemir@gmail.com, rfg822@gmail.com
}

\section{Resumo}

A Bacia Hidrográfica do Rio Meia Ponte, que abrange 37 municípios, incluindo a capital do estado de Goiás, apresenta grande pressão hídrica, principalmente, nos períodos de estiagem. Desta forma, o reúso de água, a partir do esgoto sanitário como suplemento à irrigação tradicional agrícola, se apresenta como uma prática promissora na redução desses conflitos sobre o uso da água. Assim, neste trabalho, foi avaliado o potencial de reúso de água de Estações de Tratamento de Esgoto (ETE's) em irrigação de áreas de pastagens da Bacia Hidrográfica do Rio Meia Ponte. A relação entre oferta e demanda das áreas analisadas foi obtida, respectivamente, por meio das vazões das ETE's disponibilizadas pela Agência Nacional de Águas (ANA) e pelo cálculo da demanda de água na irrigação segundo as instruções do Manual Técnico de Outorga da Secretária do Meio Ambiente e Recursos Hídricos (SEMARH). Em seguida, a qualidade dos esgotos sanitários tratados foi analisada visando ao atendimento às recomendações estabelecidas no INTERÁGUAS (2018). Realizou-se, ainda, o cálculo da estimativa de custo do transporte da água de reúso, adotando-se a metodologia desenvolvida por Araújo et al. (2017). O estudo permitiu a identificação de um atendimento de $100 \%$ da demanda de água para o uso na irrigação de pastagens localizadas no raio de 5 km da ETE de Goiânia, bem como se averiguou que o maior desafio para a prática efetiva do reúso é a ausência de regulamentação para a cobrança do uso dos recursos hídricos e de parâmetros de qualidade de água para o reúso de efluentes.

Palavras-chave: Reúso de Água; Irrigação de pastagem; Demanda hídrica; Qualidade da água.

\section{Abstract}

The Meia Ponte River Basin, which encompasses 37 cities, including the capital of the state of Goiás, endures great water pressure, especially during periods of drought. Thus, the water reuse from sanitary sewage as a supplement to traditional agricultural irrigation presents itself as a promising practice in reducing pressures over water usage. Therefore, in this work the potential of water reuse from Wastewater Treatment Plant (WWTP) in irrigation of pasture areas of the Meia Ponte River Basin was evaluated. The relationship between supply and demand in the analyzed areas was obtained, through the wastewater flow of the WWTP's made available by the Agência Nacional de Águas (ANA) and by calculating the demand according to the instructions in the Technical Grant Manual of the Secretary for the Environment and Water Resources (SEMARH). Then, the quality of the treated sanitary sewage was analyzed to meet the recommendations established in INTERÁGUAS (2018) and the calculation of the cost estimate for the transport of reused water was carried out using the methodology developed for Araújo et al. (2017). Finally, through this study, it was found that $100 \%$ of the water demand for irrigation of pastures located within a 
radius of $5 \mathrm{~km}$ from a WWTP in Goiania was met, and it was observed that the greatest challenges for effective practice of reuse of wastewater is the absence of regulations for charging the use of water resources and water quality parameters for the reuse of effluents.

Keywords: Water reuse; Pasture Irrigation; Water demand; Water quality.

\section{INTRODUÇÃO}

A escassez de recursos hídricos é um risco crescente em muitas partes do mundo, agravada pela rápida urbanização e aumento da variabilidade climática. As águas residuárias recicladas ou "reúso de água" é uma maneira promissora de aumentar a disponibilidade de recursos hídricos em áreas de escassez e contribuir para a sustentabilidade desse recurso (GRANT et al., 2012).

Segundo o 25 Diagnóstico dos Serviços de Água e Esgotos da Secretaria Nacional de Saneamento (BRASIL, 2019), na região Centro Oeste, $57,7 \%$ da população era atendida pela coleta de esgoto e o índice de tratamento de esgoto era de $56,8 \%$. Esse efluente, após o tratamento, pode ser direcionado a múltiplos propósitos, como irrigação agrícola (TAL, 2006), uso industrial (LEE; TAN, 2016) e recarga de água subterrânea (SLOAN, 2013).

Segundo 0 Atlas Irrigação da Agência Nacional de Águas (ANA, 2017), com aproximadamente $67 \%$ do consumo de água, a agricultura irrigada é o setor responsável pelo maior consumo de água no Brasil. Dessa forma, o reúso de água nas regiões agrícolas é um grande aliado na redução da pressão de corpos hídricos superficiais e subterrâneos, favorecendo a preservação da água disponível para consumo humano e dessedentação animal, além de diminuir o lançamento de efluentes em corpos hídricos (MELO et al., 2020). Esta prática também pode reduzir a demanda por fertilizantes químicos na agricultura, em função das consideráveis concentrações de nutrientes no esgoto sanitário. Tal prática de reúso é conhecida com fertirrigação.

Sabe-se que a pressão hídrica tem acontecido em diversas bacias de mananciais de abastecimento no estado de Goiás, estando a Bacia Hidrográfica do Rio Meia Ponte inserida neste cenário. A Bacia apresenta uma área de drenagem de $12.180 \mathrm{~km}^{2}$, compreendendo 37 municípios, dos quais se destaca a capital do estado de Goiás, Goiânia, e representa 3,56\% da área territorial do estado (COELHO FILHO, 2015;
SEMARH, 2001).

A pluviometria característica no território da Bacia é típica do bioma Cerrado, uma vez que apresenta um período chuvoso, de outubro a abril, e um período seco, de maio a setembro (MARCUZZO et al., 2012). Tais características pluviométricas acarretam variabilidade mensal na disponibilidade de água, com consequente deficiência hídrica no período de estresse e excedência nos demais meses. Assim, ao se analisar o panorama global da referida bacia, com base em diferentes indicadores relacionados às demandas de usos dos recursos hídricos, identificaram-se os graus de pressão sobre os recursos hídricos por sub-bacias. Para a demanda de irrigação, verificou-se que a maioria absoluta das sub-bacias possui um grau de pressão classificado como alto (SEMAD, 2020).

Nesse sentido, o reúso de água a partir do esgoto sanitário na bacia do Rio Meia Ponte se apresenta como uma prática promissora na redução das pressões sobre o uso da água nos períodos de estiagem. Dentre as diversas possibilidades de reúso, a sua aplicação como suplemento à irrigação tradicional agrícola é benéfica em virtude do consumo de água demandado pelo setor agropecuário na bacia em estudo.

Assim, o presente artigo apresenta uma avaliação do potencial do reúso de efluente de água, a partir de efluentes de Estações de Tratamento de Esgoto (ETE's), em irrigação de áreas de pastagens da Bacia Hidrográfica do Rio Meia Ponte, considerando a demanda de água para irrigação e a disponibilidade e qualidade dos esgotos sanitários tratados.

\section{METODOLOGIA}

\section{Etapa 1: Seleção das Estações de Tratamento de Esgoto}

A escolha da Bacia do Rio Meia Ponte (Figura 1), localizada no estado de Goiás, para o desenvolvimento deste trabalho, é justificada em decorrência do nível de pressão exercida pela 
demanda de irrigação, conforme exposto em SEMAD (2020), estudo este que determinou que a bacia em sua totalidade se encontra sob alta pressão sobre os seus recursos hídricos.
Esta bacia possui 29 Estações de Tratamento de Esgoto nas 37 cidades que a compõem, cujas localizações e vazões são disponibilizadas no Catálogo de Metadados da ANA (2019).

\section{Figura 1: Localização da Bacia do Rio Meia Ponte no mapa de Goiás}

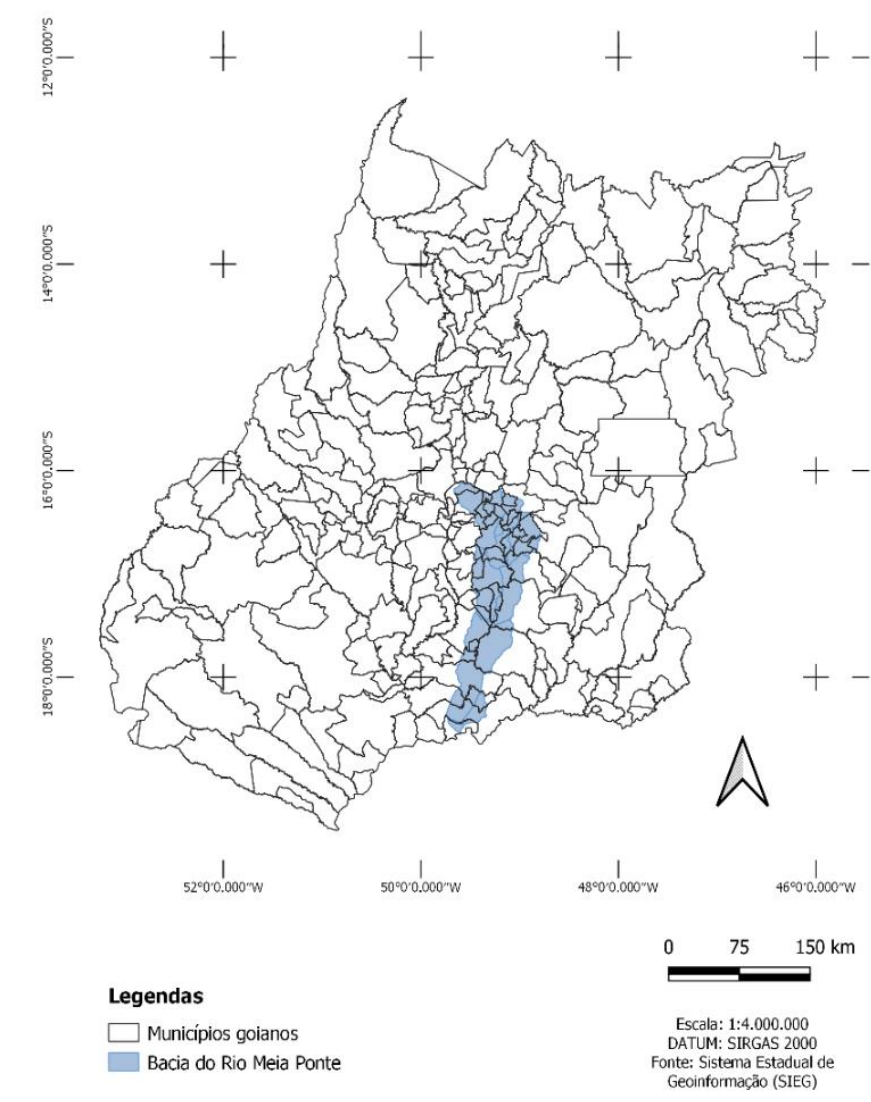

Fonte: Autores (2021).

\section{Etapa 2: Demarcação da área irrigada na região de estudo}

Visando a determinar as áreas que seriam potencialmente beneficiadas pela irrigação por água de reúso, utilizaram-se os dados de uso de solo disponibilizados pela plataforma Mapbiomas da Coleção 5.0 (2019) para identificar os tipos de culturas encontradas na área da bacia.

Posteriormente, buscando-se definir uma área de irrigação viável, foi realizada uma análise preliminar das áreas de estudo. Testaram-se diferentes raios de atendimento, em fatores de múltiplos de 5 , de 5 a $30 \mathrm{~km}$. Por fim, com base na baixa disponibilidade de vazão de água de reúso de grande parte das ETEs em estudo, selecionou-se $\circ$ raio de $5 \mathrm{~km}$ a partir da localização das estações selecionadas.

Todos os dados de geoprocessamento foram tratados utilizando-se das ferramentas disponibilizadas pelo software gratuito - Quantum - GIS, um sistema de informação geográfica e licenciado sob a General Public License (GNU).

\section{Etapa 3: Cálculo da oferta e demanda de água na irrigação}

Uma vez identificadas e selecionadas as ETE's que possuem vazão de operação com capacidade para reúso e limitadas às áreas a serem irrigadas a um raio de $5 \mathrm{~km}$, calculou-se a demanda de água para a irrigação da área selecionada para cada ETE em análise. 
O cálculo da demanda de água foi realizado conforme disposto no Manual Técnico de Outorga (SEMARH, 2012). Nesse método, é necessária a determinação da área irrigada (Ai), da quantidade de água disponível naturalmente por meio da precipitação $(\mathrm{Tm})$, da quantidade de água perdida por meio da evapotranspiração (Etc), das perdas envolvidas nos sistemas de irrigação (Ei) e das práticas agrícolas da região.

Para obtenção das médias mensais de precipitação $(\mathrm{Tm})$ e da evapotranspiração de referência (Eto), utilizou-se a base de dados da Organização das Nações Unidas para a Alimentação e a Agricultura (FAO): FAOCLIM (2021). A base apresenta dados de $30 \mathrm{mil}$ estações no mundo. Quanto ao território brasileiro, apresenta dados de 1.503 estações com precipitação média mensal e 798 com evapotranspiração de referência.

Os dados fornecidos por tal base foram estimados pelo método considerado padrão, que é o Penman/Montheith/FAO, por meio de um programa de interpolação fornecido pela $F A O$, o New_LocClim 1.10 - Local Climate Estimator. O software permitiu que as variáveis de interesse, evapotranspiração de referência e precipitação média mensal fossem estimadas para cada ETE de interesse.

As perdas envolvidas nos sistemas de irrigação estão relacionadas à eficiência de irrigação (Ei). A eficiência de irrigação, nesse método, é a relação entre o volume mensal correspondente às necessidades de irrigação líquida e o volume mensal de captação para irrigação da respectiva área, englobando, portanto, as perdas da captação, condução e aplicação (SEMARH, 2012).

No Manual Técnico de Outorga (SEMARH, 2012), são apresentados valores de eficiências mínimas para diferentes métodos de irrigação.
Para este trabalho, adotou-se o valor de Ei em $80 \%$, uma vez que, para pastagens, a aspersão em malha é o método mais utilizado atualmente para a irrigação de áreas pequenas (até 40 hectares) (RICHTER, 2019). Segundo esse autor, tal sistema, que derivou dos conjuntos fixos de aspersão convencional, pode ser montado até 99\% em PVC, o que reduz o desgaste quando é utilizado para aplicação de fertirrigação e, consequentemente, para reúso de água.

Para se considerar as práticas agrícolas da região, utiliza-se nesse método o coeficiente de cultura $(\mathrm{Kc})$ que se refere à relação entre a evapotranspiração da cultura (ETc), em determinado estágio de desenvolvimento, e a evapotranspiração de referência (ETo) (SEMARH, 2012). Na literatura, são apresentados valores de $\mathrm{Kc}$ para as diferentes culturas e seus estágios de desenvolvimento.

Dessa forma, obteve-se no Manual Técnico de Outorga o valor médio de 0,6 para o Kc da cultura pastagem extensiva, categoria das forrageiras. Utilizou-se a média dos Kc's (inicial, médio e final) a fim de se atender a Nota Técnica $n^{\circ}$ 01/2013-SRH (SEMARH, 2013), a qual determina que, para os cálculos de lâmina para irrigação, deve ser usada a média dos Kc's.

Adotados todos os parâmetros dos fatores que influem na demanda de água para irrigação, quantificaram-se as precipitações mensais prováveis (PMP) - Equação 1, as precipitações efetivas prováveis (Pp\%) - Equação 2, a evapotranspiração da cultura (Etc) - Equação 3, a necessidade de irrigação líquida (NIL) - Equação 4, a necessidade de irrigação bruta (NIB) Equação 5, e volume mensal de captação necessário (Vmn) - Equação 6. Todas as fórmulas utilizadas no cálculo das demandas mensais de água para a irrigação foram obtidas no Manual Técnico de Outorga (SEMARH, 2012).

$$
\begin{aligned}
& P M P=(0,6 * T M)-10(\text { Para } T M<70 \mathrm{~mm}) \\
& P M P=(0,8 * T M)-24(\text { Para } T M>70 \mathrm{~mm}) \\
& P p \%=P M P *((125-(0,2 * \text { PMP })) / 125(\text { Para } P M P<250 \mathrm{~mm}) \\
& P p \%=125+(0,1 * \text { PMP })(\text { Para PMP }>250 \mathrm{~mm}) \\
& \text { Etc }=\text { Eto } . K c \\
& \text { NIL }=\text { Etc }- \text { Pp\% } \\
& \text { NIB }=100 \cdot(\text { NIL } / \text { Ei }) \\
& \text { Vmn }=10 \cdot(\text { NIB } . A i)
\end{aligned}
$$

Sendo:

TM: Total mensal de precipitação ( $\mathrm{mm} / \mathrm{mês}$ ) 
PMP: Precipitação mensal provável ( $\mathrm{mm} / \mathrm{mês}$ )

PP\%: Precipitação efetiva provável $(\mathrm{mm} / \mathrm{mês})$

Eto: Evapotranspiração de referência ( $\mathrm{mm} / \mathrm{mês})$

kc: Coeficiente de cultura

Etc: Evapotranspiração da cultura ( $\mathrm{mm} / \mathrm{mês})$

NIL: Necessidade de irrigação líquida ( $\mathrm{mm} / \mathrm{mês}$ )

Ei: Eficiência do uso da água na irrigação (\%)

NIB: Necessidade de irrigação bruta ( $\mathrm{mm} / \mathrm{mês}$ )

Ai: Área irrigada (ha)

Vmn: Volume mensal necessário para irrigação (m3/mês)

A partir dos volumes mensais necessários para irrigação obtidos, foi possível comparar a oferta de água de reúso gerada nas ETE's em estudo e as demandas de água para irrigação nas áreas escolhidas. Também se tornou possível a verificação de quais meses do ano é necessária a irrigação, e qual a área máxima que a vazão de cada ETE consegue atender no mês mais crítico, identificando, portanto, o potencial quantitativo de reúso para a Bacia do Meia Ponte.

\section{Etapa 4: Comparação da qualidade da água de reúso e o padrão de exigência}

Um dos critérios de seleção das ETE's estudadas neste trabalho foi a disponibilidade de dados a respeito da vazão de operação e qualidade do efluente tratado. Para execução deste estudo, os dados de qualidade foram fornecidos pela Companhia de Saneamento do Estado de Goiás (SANEAGO), por meio da disponibilização dos Relatórios de Ensaio de Esgoto realizados mensalmente durante anos de 2019 e 2020. A partir daí, realizaram-se avaliações em relação ao atendimento do volume do efluente e à recomendação estabelecida no INTERÁGUAS (2018) para reúso agrícola restrito, sendo este um documento normativo/norteador federal, uma vez que o Brasil ainda não possui regulamento mandatório sobre reúso de água em nível federal.

\section{Etapa 5: Análise do custo de transporte por caminhão pipa}

O cálculo da estimativa de custo do transporte da água de reúso foi realizado adotando-se a metodologia desenvolvida por Araújo et al. (2017). Com o emprego desta metodologia, procedeu-se a estimativa do custo do transporte das águas de reúso em caminhão pipa da ETE até a área irrigada. Para isto, adotou-se o uso de caminhão pipa de $6 \mathrm{~m}^{3} \mathrm{e}$ obteve-se o valor do transporte de água, através do código 5747 do Sistema Nacional de Pesquisa de Custos e Índices da Construção Civil (SINAPI, 2021), para o estado de Goiás, de março de 2021. Também foi necessário se adotar uma velocidade média do caminhão de $60 \mathrm{~km} / \mathrm{h}$, conforme o mesmo autor, para em seguida se utilizar a Equação 8 para o cálculo da distância e o tempo utilizado.

$$
V\left(\frac{k m}{h}\right)=(\Delta S(k m)) /(\Delta T(h))
$$

A bacia estudada não possui atualmente cobrança pelo uso da água na irrigação. Desta forma, foi realizada uma análise a respeito das cobranças praticadas no nível nacional, tais como na Bacia do Paraíba do Sul. Posteriormente, efetuou-se uma comparação entre o valor médio da água bruta cobrado nas demais bacias e o custo da água de reúso, baseado principalmente no custo de transporte.

\section{RESULTADOS}

\section{Etapa 1: Seleção das Estações de Tratamento de Esgoto}

Dentre as 29 estações de tratamento de esgoto da Bacia do Rio Meia Ponte, foram selecionadas, para este trabalho, as ETE's que se encontram nos limites da Bacia ou em suas proximidades. Subsequentemente, entre as ETE's remanescentes, utilizou-se como critério de exclusão a disponibilidade de dados de vazões e o status da estação, ativa ou inativa, resultando, assim, em um total de doze ETE's de interesse para este estudo (Figura 2).

Observa-se que no caso de Goiânia, em especial, selecionou-se apenas a ETE Dr. Hélio Seixo de Britto, visto que esta possui a vazão mais significativa. Ademais, outras seis estações existentes em Goiânia não possuíam os dados 
necessários para o desenvolvimento deste trabalho.

\section{Etapa 2: Demarcação da área irrigada na região de estudo}

Entre os usos de solo presentes no estado, observaram-se, na bacia em questão, cinco tipos de uso aptos para irrigação por reúso: cana, soja, pastagem, lavouras perenes e outras lavouras temporárias (Figura 3). Destes usos, elegeram-se para irrigação com água de reúso as áreas de pastagem, por compreenderem uma área territorial de maior significância no estado de Goiás, especialmente no interior da bacia analisada. Ademais, a escolha faz-se pertinente devido à importância da pecuária como setor de produção, contribuindo notavelmente no produto interno bruto brasileiro. Segundo o Instituto Mauro Borges (2018), a pecuária goiana conta com 21,9 milhões de cabeças, representando $10,2 \%$ do rebanho nacional.

A Figura 4 apresenta as áreas de pastagem presentes dentro de um raio de $5 \mathrm{~km}$ das ETE's selecionadas, as quais seriam potencialmente beneficiadas pela irrigação por água de reúso. Atenta-se que as pastagens representadas em rosa na Figura 4, apesar de situadas no interior do raio de estudo, não são pertencentes à Bacia do Rio Meia Ponte, portanto, foram desconsideradas.

Após a identificação das áreas de pastagem dentro dos raios de interesse, calcularam-se, com - auxílio do software de geoprocessamento QGIS, as dimensões dessas áreas em hectares. As áreas de pastagem em hectares, assim como as vazões, conforme dispostas no Catálogo de Metadados da ANA (2019), estão expostas na Figura 5.

Figura 2: Localização das ETE's de interesse para este estudo

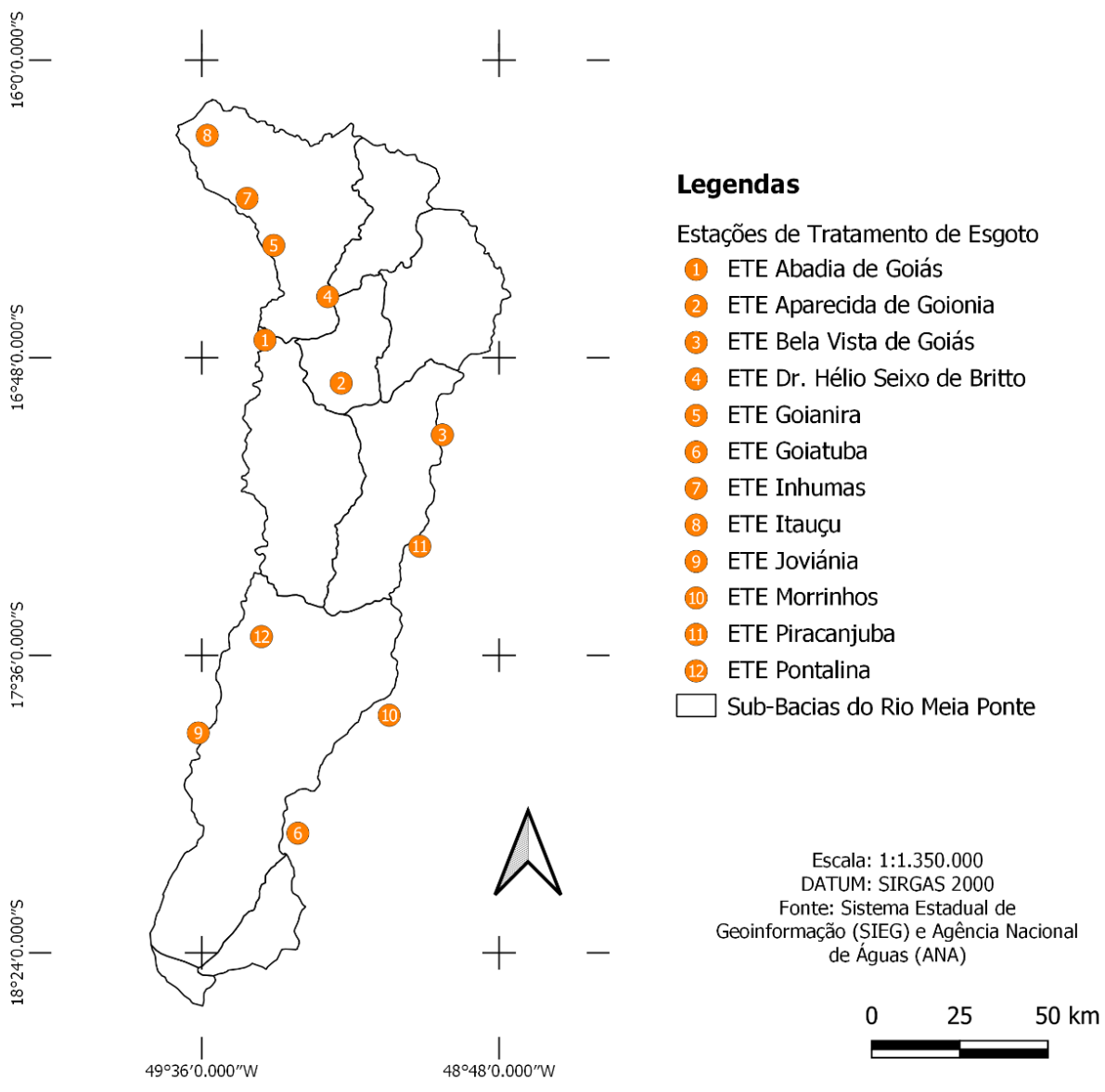

Fonte: Autores (2021) 
Figura 3: Uso de solo da Bacia do Rio Meia Ponte

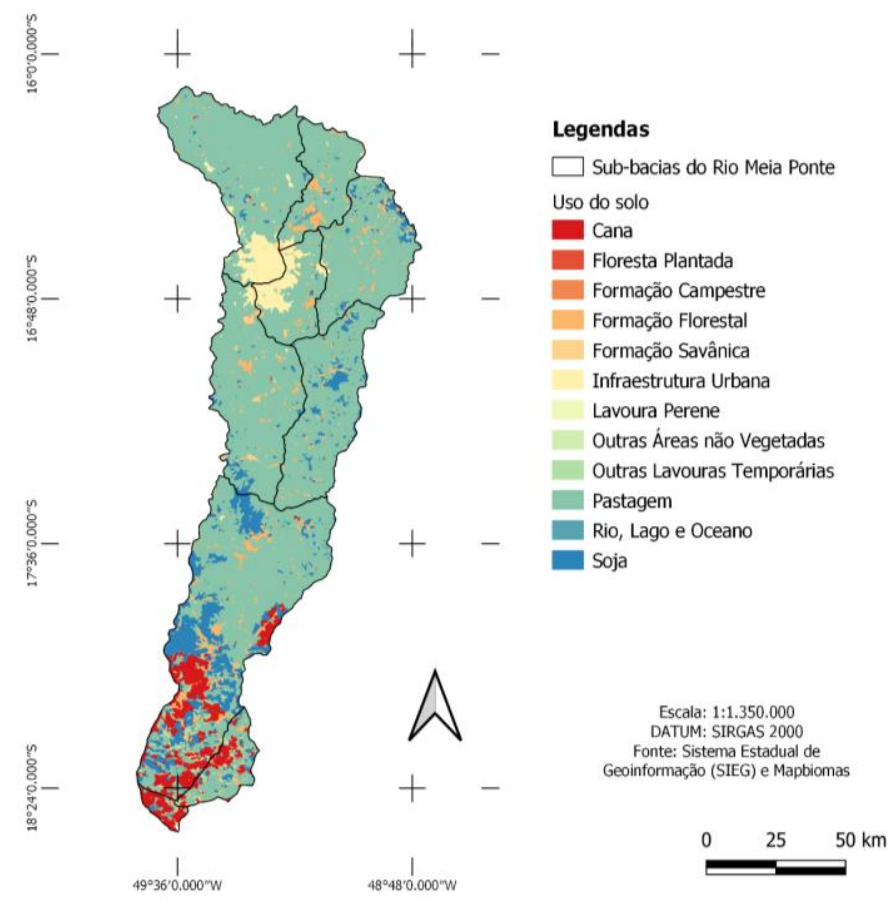

Fonte: Autores (2021).

Figura 4: Localização das ETE's e áreas de pastagem encontradas em um raio de $5 \mathrm{~km}$ das mesmas

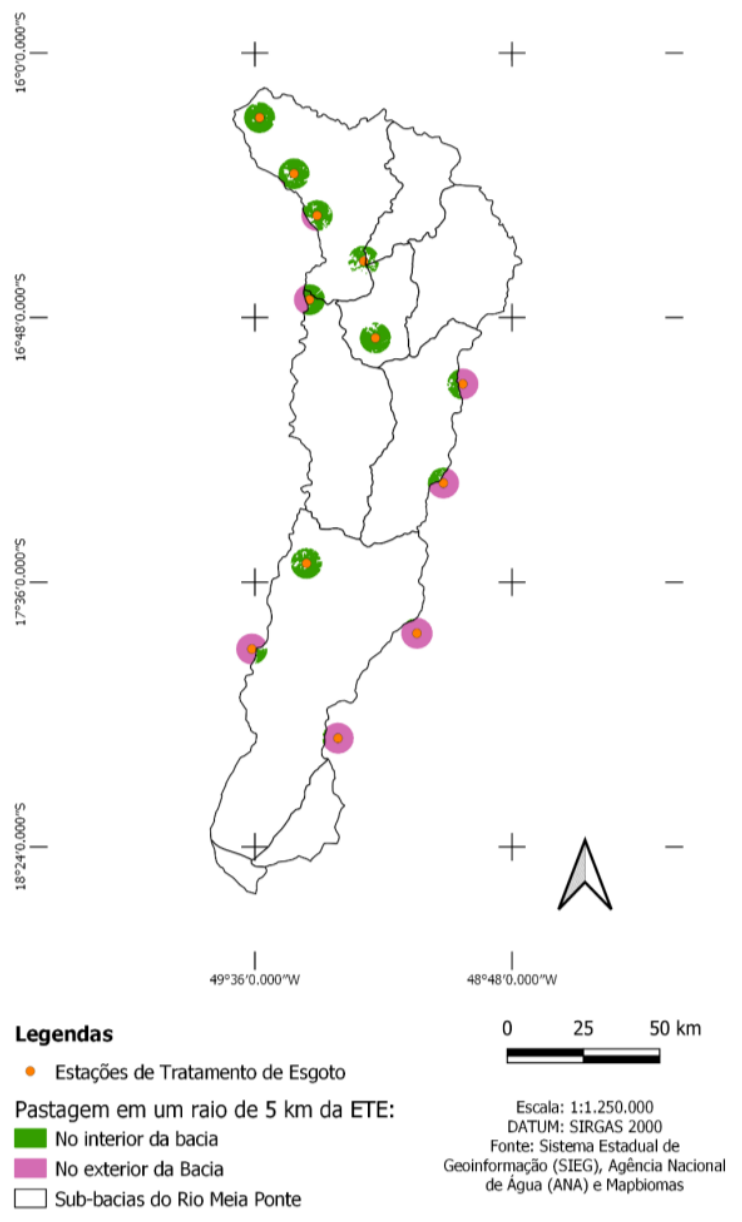

Fonte: Autores (2021). 


\section{Figura 5: Áreas de pastagem e vazão da estação de tratamento de esgoto por município de interesse}

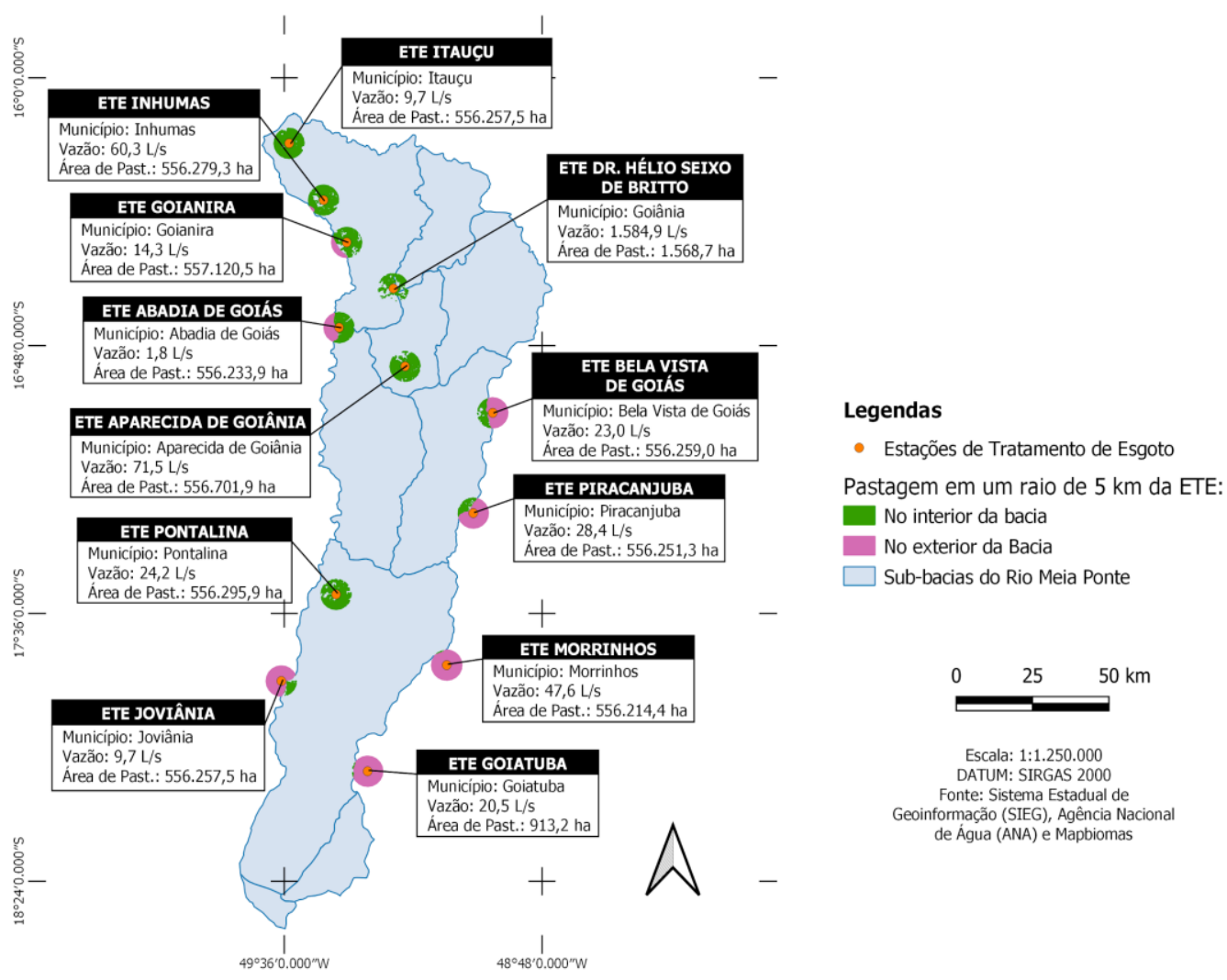

Fonte: Autores (2021).

\section{Etapa 3: Cálculo da oferta e demanda de água na irrigação}

Uma vez obtidas as coordenadas e a vazão média mensal das ETEs selecionadas para estudo e limitadas às áreas de pastagem para 0 raio de $5 \mathrm{~km}$, obtiveram-se as demandas mensais de água para a irrigação de cada área.

Por meio dos cálculos, foi possível notar que os períodos de outubro a março não necessitam de irrigação nas áreas em estudo, visto que esses meses possuem um balanço hídrico vertical positivo, ou seja, considerando-se somente 0 movimento vertical de água dentro do solo, precipitação e evapotranspiração, a quantidade líquida de água que permanece disponível é suficiente às plantas (INPE, 2005).

Já nos meses de abril a setembro, obteve-se demanda de água para a irrigação. Assim, nesses meses de veranico, a irrigação é necessária para que a pastagem cresça normalmente, uma vez que a precipitação do período de estiagem não é suficiente para o desenvolvimento das culturas.
Ao calcular a demanda de água na irrigação, constatou-se que o mês de agosto é o mais crítico do ano para todas as áreas em estudo. $\mathrm{O}$ período é caracterizado por um balanço hídrico com baixa precipitação e alta evapotranspiração, - que acarreta o déficit hídrico no armazenamento de água no solo. Segundo Silva Junior et al. (2018), o mês de agosto também é considerado o mês mais crítico para a agricultura irrigada na região noroeste do estado de São Paulo.

Desta forma, na Tabela 1, é possível observar a relação entre a potencial oferta de água de reúso, vazão da ETE e a demanda de água para irrigação de pastagem no raio adotado para o mês de agosto. Ainda na Tabela 1, é mostrada a área máxima que cada ETE consegue irrigar e o percentual de atendimento de cada ETE.

A área máxima foi obtida levando-se em consideração a vazão média mensal de cada ETE e a demanda de água para irrigação no mês mais crítico. Assim, essa área representa a máxima 
extensão que cada ETE consegue irrigar durante todo o ano, ou seja, apesar de nos demais meses do ano as estações conseguirem atender áreas maiores, devido à precipitação, a área máxima constitui a extensão atendida o ano todo.

Já o percentual de atendimento de cada ETE representa a razão entre a área máxima que a
ETE consegue irrigar no mês de agosto (área máxima) e a área de pastagem compreendida no raio de $5 \mathrm{~km}$. Dessa forma, esse percentual representa a razão entre a oferta de água de reúso e a demanda de água para irrigação.

Tabela 1: Capacidade de atendimento de irrigação de pastagem em relação as vazões das ETE's da Bacia do Rio Meia Ponte

\begin{tabular}{cccccc}
\hline Cidade & $\begin{array}{c}\text { Vazão } \\
\text { Média } \\
\text { da } \\
\text { ETE } \\
\text { (L/s) }\end{array}$ & $\begin{array}{c}\text { Área de } \\
\text { Pastage } \\
\text { m (ha) }\end{array}$ & $\begin{array}{c}\text { Demanda de } \\
\text { atendimento } \\
\text { do mês de } \\
\text { agosto (L/s) }\end{array}$ & $\begin{array}{c}\text { Área } \\
\text { Máxima } \\
\text { Atendida } \\
\text { (ha) }\end{array}$ & $\begin{array}{c}\text { Percentual } \\
\text { de } \\
\text { Atendiment } \\
\text { o (\%) }\end{array}$ \\
\hline $\begin{array}{c}\text { Abadia de } \\
\text { Goiás }\end{array}$ & 1,80 & $556.233,9$ & $218.377,4$ & 4,6 & 0,001 \\
\hline $\begin{array}{c}\text { Aparecida } \\
\text { de } \\
\text { Goiânia }\end{array}$ & 71,50 & $556.701,9$ & $218.561,1$ & 182,1 & 0,033 \\
\hline $\begin{array}{c}\text { Bela Vista } \\
\text { de Goiás }\end{array}$ & 23,00 & $556.259,0$ & $218.387,2$ & 58,6 & 0,011 \\
\hline Goiânia & 1.584, & $1.568,7$ & 615,9 & $4.036,9$ & 100,0 \\
\hline Goianira & 14,30 & $557.120,5$ & $218.725,5$ & 36,4 & 0,007 \\
\hline Goiatuba & 20,50 & 913,2 & 270,5 & 69,2 & 7,578 \\
\hline Inhumas & 60,30 & $556.279,3$ & $218.395,2$ & 153,6 & 0,028 \\
\hline Itauçu & 9,70 & $556.257,5$ & $218.386,7$ & 24,7 & 0,004 \\
\hline Joviânia & 10,80 & $3.554,9$ & $1.383,2$ & 27,8 & 0,781 \\
\hline Morrinhos & 47,60 & $556.214,4$ & $207.571,8$ & 127,6 & 0,023 \\
\hline Piracanju & 28,40 & $556.251,3$ & $218.384,2$ & 72,3 & 0,013 \\
\hline ba & & & & 61,6 & 0,011 \\
\hline Pontalina & 24,20 & $556.295,9$ & $218.401,7$ & 6 & \\
\hline
\end{tabular}

Fonte: Autores (2021).

Conforme a Tabela 1, com exceção da ETE de Goiânia, o volume de efluente das ETE's em análise não atenderiam mais que $8 \%$ da demanda de água da área de pastagem compreendida no raio de $5 \mathrm{~km}$. Em $75 \%$ das ETE's, as áreas de pastagem, no raio de $5 \mathrm{~km}$, se encontram em torno de 556.000 ha. Essas áreas, significativas, combinadas às baixas vazões mensais das ETE's, menores que $75 \mathrm{~L} / \mathrm{s}$, contribuíram para o baixo percentual de atendimento.

No entanto, nas ETE's de Goiânia, Goiatuba e Joviânia, as áreas de pastagem são menores que 4.000 ha. Em Joviânia, apesar de a área ser relativamente pequena, 0 percentual de 
atendimento não consegue atingir $1 \%$, visto que a vazão de efluente tratado mensal é pequena, 10,8 L/s. Em Goiatuba, o atendimento é o segundo maior da bacia, conseguindo atingir $7,6 \%$. Tal percentual deve-se ao município apresentar a menor área irrigada, o que elevou sua taxa, ainda que a vazão da ETE seja relativamente baixa.

$O$ valor encontrado para o percentual de atendimento em Goiatuba pode ser comparado ao resultado obtido por Araújo et al. (2020), em que, avaliando o potencial de reúso de efluentes em áreas irrigadas da Bacia Hidrográfica Piancópiranhas-açu, constatou-se que a oferta de água de reúso representa $8 \%$ da demanda de água para irrigação.

Em outro estudo semelhante, ao analisar o potencial de uso de efluentes doméstico tratado para irrigação na Bacia do Rio Paracatu, Melo et al. (2020) concluíram em seu trabalho que o volume de efluente tratado conseguiria suprir apenas $4,6 \%$ da demanda para a irrigação.

Os resultados obtidos por Araújo et al. (2020) e Melo et al. (2020) contribuem para o entendimento dos resultados deste presente trabalho, em que, em 10 das 12 ETE's analisadas, a oferta de água de reúso representa menos de $1 \%$ da demanda de água para irrigação. Os percentuais de atendimento, apesar de se mostrarem muito baixos à primeira vista, não são totalmente discrepantes após a análise desses outros estudos.

No entanto, em todas as ETE's há a possibilidade de aumento do percentual de atendimento se houver a reserva de água nos meses cuja demanda hídrica é nula (outubro a março). Assim, os pequenos reservatórios, que viabilizariam 0 processo de irrigação durante 0 período de estiagem, podem ser estimados através de modelos matemáticos, como o de Schosklisch, os quais permitem a estimativa do volume de água em reservatórios de irrigação (ROBAINA, 2009).

A vazão média mensal da ETE de Goiânia representa $83,55 \%$ da vazão conjunta de todas as ETE's em estudo. Assim, por se ter uma alta vazão, de aproximadamente $1.500 \mathrm{~L} / \mathrm{s}$, e uma área relativamente pequena, aproximadamente 1.500 ha, Goiânia se destaca como a única cidade que conseguiria irrigar $100 \%$ da área de pastagem no raio de $5 \mathrm{~km}$ da ETE. Ademais, a ETE ainda conseguiria atender mais 2.468,2 ha de área de pastagem que se encontram além dos $5 \mathrm{~km}$ considerados no estudo.

\section{Etapa 4: Comparação da qualidade da água de reúso e o padrão de exigência}

Em geral, nos instrumentos regulatórios, a classificação quanto à condição do reúso agrícola ser restrita ou irrestrita depende da magnitude do risco de contaminação microbiológica a que estão expostos os trabalhadores e os usuários da água de reúso. Em todos os casos, os padrões mais restritivos se aplicam às culturas com maior possibilidade de contato com a água de reúso (aquelas que se desenvolvem rente ao solo, como tubérculos e hortaliças) e que podem ser consumidas cruas. Os limites mais lenientes normalmente se aplicam a culturas cujos produtos serão consumidos após processamento, a exemplo das frutíferas, arbóreas, cerealíferas e forrageiras (INTERÁGUAS, 2018).

Quanto à qualidade do efluente tratado, foram analisadas apenas onze ETE's, visto que a ETE Aparecida de Goiânia não possuía dados disponíveis no que se refere a essa questão. Dentre as ETE's com dados de qualidade disponíveis, apenas uma não é composta pela associação em série de lagoas de estabilização. Trata-se da ETE Goiânia, dotada de um sistema do tipo Tratamento Primário Quimicamente Assistido (TPA), que utiliza produtos químicos (coagulantes e floculantes) para remover sólidos suspensos e coloidais presentes no esgoto. A opção por essa tecnologia seguramente foi uma decorrência da necessidade de se compactar a ETE e reduzir sua área de implantação, a despeito da qualidade inferior do efluente tratado, que dificilmente poderá ser aproveitado para o reúso agrícola nas condições atuais. Nas demais, os fluxogramas de tratamento terminam com uma lagoa de maturação, que vem a ser um processo com finalidade de remover microrganismos patogênicos e reduzir a concentração de microalgas no efluente tratado.

Tendo em vista o tipo de reúso almejado (irrigação de pastagens), observa-se que o instrumento regulatório a ser considerado é que determinará a necessidade de reforma das ETE's em questão. Na Figura 6, estão os gráficos do tipo Boxplot, nos quais são apresentados os resultados de qualidade do efluente das onze ETE's analisadas, para os parâmetros pH, DBO, Turbidez e E.Coli.

Considerando a diretiva INTERÁGUAS (2018) como instrumento de referência para avaliação da aplicabilidade do reúso proposto, 
somente o parâmetro $\mathrm{pH}$ atende às exigências de qualidade (à exceção da ETE Goiatuba), o que impossibilita o reúso nas atuais situações em que se encontra a eficiência das ETE's, já que existe a necessidade de atendimento a outros parâmetros, como coliformes termotolerantes, ovos de helmintos, turbidez, DBO e Cloro residual. Obviamente, se 0 instrumento regulatório selecionado for mais restritivo do que o INTERÁGUAS (2018) em termos de qualidade da água de reúso, maior será a necessidade de intervenções nas ETE's consideradas neste estudo. A esse respeito, uma análise detalhada dos padrões de qualidade de água de reúso para diversos fins, estabelecidos por diferentes instrumentos regulatórios disponíveis no Brasil, encontra-se em SANTOS et al. (2020).

Figura 6: Qualidade do efluente das onze ETE's analisadas, para os parâmetros pH, DBO, Turbidez e E.Coli. (diagramas de caixa)

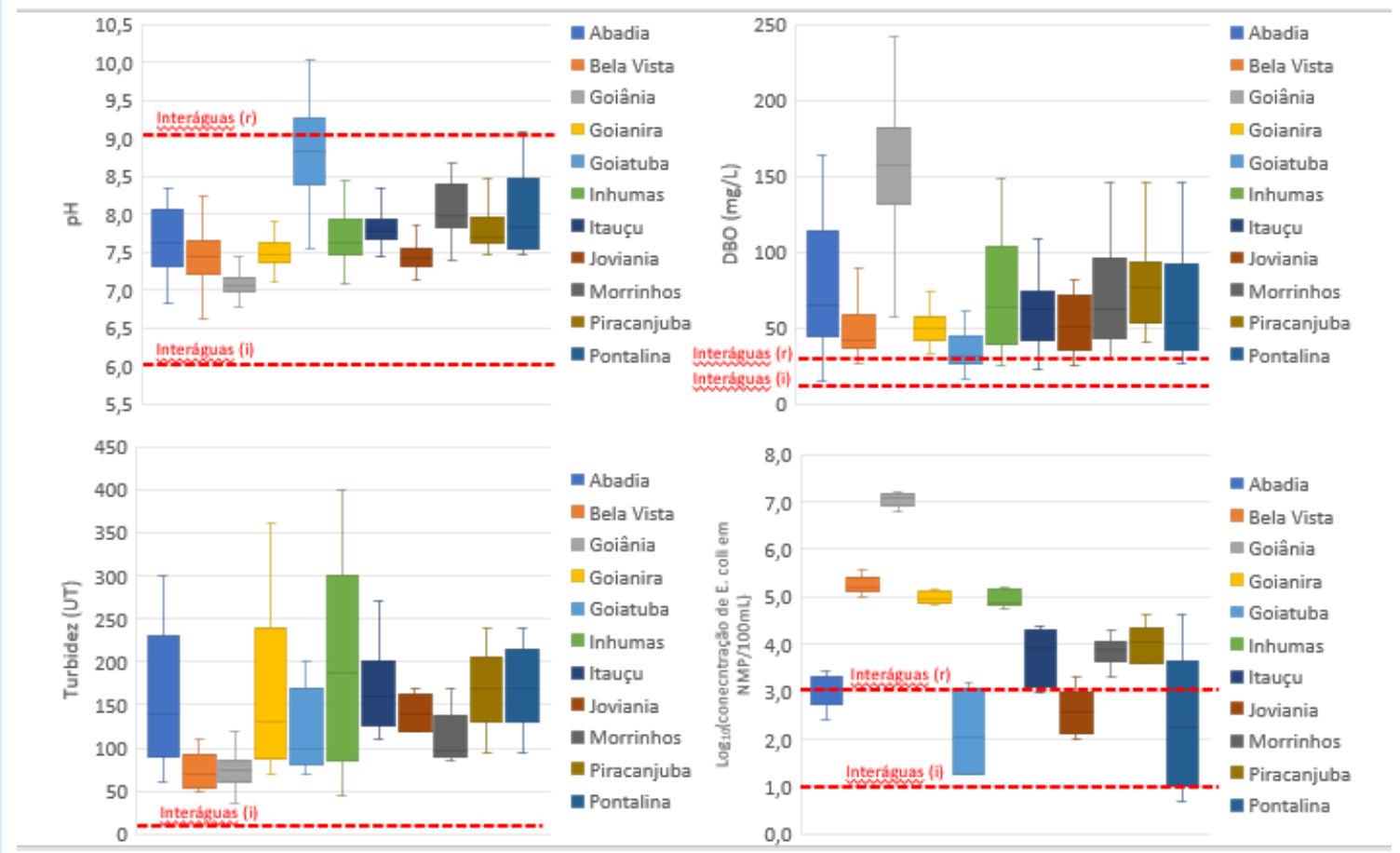

Fonte: Autores (2021).

Nota: Interáguas (i) - padrão de qualidade para reúso agrícola irrestrito, INTERÁGUAS, 2018.

Interáguas ( $r$ - - padrão de qualidade para reúso agrícola restrito, INTERÁGUAS, 2018.

O parâmetro turbidez na água de reúso é considerado importante por alguns pesquisadores, e integra muitos instrumentos regulatórios do reúso de água por ter uma relação direta com os sólidos suspensos no esgoto tratado. Argumenta-se que os sólidos em suspensão podem oferecer um nicho de proteção a microrganismos patogênicos, reduzindo, assim, a eficiência dos processos de desinfecção (LIBÂNIO, 2016). Entretanto, isso não faz muito sentido em lagoas de estabilização, em cujos efluentes a grande maioria dos sólidos em suspensão é constituída pela biomassa microalgácea. Por tal motivo, o PROSAB (FLORÊNCIO et al., 2006) propõe que não haja restrições às concentrações de DBO, DQO e SST nos efluentes dedicados ao reúso, por entender que as concentrações desses parâmetros serão uma consequência das técnicas de tratamento empregadas, e que estas devem ser selecionadas em função da qualidade microbiológica almejada. Não obstante, à luz do INTERÁGUAS (2018), nenhuma das onze ETE's analisadas é capaz de produzir água para reúso agrícola (restrito ou irrestrito). Para adequá-las, será necessário um estudo para a implantação adicional de unidades de tratamento, podendo ser adotados sistemas de remoção físico-química (coagulação - floculação - sedimentação) das microalgas dos efluentes das lagoas, além de 
etapas complementares de filtração rápida em leitos arenosos e de cloração (GONÇALVES et al., 2003), bem como outros tratamentos já consolidados. No caso da grande ETE de Goiânia, o tratamento físico-químico não apresenta resultados na remoção dos compostos orgânicos solúveis do esgoto, o que sugere a necessidade de ser complementado por uma etapa de tratamento biológico (possivelmente, lodos ativados ou similar). $\mathrm{O}$ investimento para se alcançar esse nível de eficiência, indubitavelmente, será muito elevado.

Considerando-se a proposta de INTERÁGUAS (2018), observa-se que somente a ETE Joviania seria capaz de produzir, consistentemente, um efluente tratado compatível com reúso agrícola restrito sem a necessidade de melhorias no sistema de tratamento. Nenhum dos efluentes das onze ETE's seria compatível com o reúso irrestrito nas condições em que elas se encontram atualmente. Porém, se o instrumento de referência for a deliberação normativa de Minas Gerais (2020), cinco ETE's (Abadia, Goiatuba, Joviania, Morrinhos e Pontalina) atenderiam, de forma consistente, o padrão $E$. coli para reúso agrícola irrestrito. Ainda, à exceção da ETE Goiânia, todas as demais seriam capazes de produzir água para reúso agrícola restrito nas condições em que se encontram hoje em dia.

Outro parâmetro presente em vários instrumentos regulatórios do reúso de água é o "cloro residual", sob a justificativa de oferecer uma garantia de proteção da água durante a distribuição e a reservação. Porém, a cloração, no caso de ETE's com lagoas de maturação como etapa final de tratamento, só faz sentido ao se considerar a reservação, pelo fato de que essas lagoas já são a etapa de desinfecção. Além disso, a cloração de efluentes ricos em microalgas não é recomendável, não só pelo alto consumo do desinfetante, como também pela possibilidade de formação de subprodutos tóxicos no efluente tratado. Ademais, o cloro é potencialmente danoso à estrutura do solo e às plantas irrigadas com água de reúso (GONÇALVES et al., 2003).

Os resultados deste estudo reforçam as observações de Santos et al. (2020) a respeito da importante discrepância conceitual $e$, consequentemente, de conteúdo entre os vários instrumentos regulatórios da prática do reúso de água no Brasil. Isso tem um impacto direto na prática do reúso nas microrregiões em que estão inseridas as onze ETE's analisadas, podendo exigir reformas importantes e dispendiosas dos sistemas de tratamento, no caso de adoção de padrões de qualidade de água de reúso e no caso de adoção de critérios muito restritivos (como os do INTERÁGUAS (2018). Por outro lado, se $O$ instrumento regulatório a ser considerado seguir as orientações do PROSAB (FLORÊNCIO et al., 2006), como é o caso da legislação de Minas Gerais (2020), com padrões menos restritivos, baseados na aplicação da metodologia de "Avaliação Quantitativa de Risco Microbiológico", algumas das ETE's em questão poderão ser transformadas imediatamente em estações produtoras de água de reúso, sem ou com pequenas alterações de infraestrutura.

Esta medida permitirá a adaptação do nível de referência de risco a técnicas de tratamento já existentes com base em uma abordagem de benefícios de risco. A sua implementação viabilizará a continuidade do uso das lagoas de estabilização existentes, que podem produzir resultados dentro de limites aceitáveis de risco à saúde humana e ser replicados de maneira sustentável pelo estado de Goiás. Ao contrário, o regramento muito restritivo exigirá um grande esforço para se viabilizar o reúso de água em uma região muito necessitada, sem que se considerem os benefícios correspondentes.

\section{Etapa 5: Análise do custo de transporte por caminhão pipa}

Segundo a OCDE (2017) o valor médio cobrado nas bacias hidrográficas interestaduais é de $R \$ 0,02 / \mathrm{m}^{3}$ para captação. Com base no cálculo realizado para se obter o custo do transporte do efluente, foi possível notar que o valor do transporte para a distância de $5 \mathrm{~km}$ é de $\mathrm{R} \$ 1,63 / \mathrm{m}^{3}$. Essa distância foi adotada tendo em vista que o valor cobrado pela OCDE (2017) é extremamente baixo para a comparação com um possível valor de transporte do efluente para o reúso, sendo que essa situação - a grande diferença dos custos - promove o desinteresse do usuário pela água de reúso, não demonstrando a importância da água na bacia para a manutenção da vida humana.

Há de se considerar que as cobranças pelos recursos hídricos no Brasil possuem suas diretrizes regidas pela Lei Federal n. 9.433/1997, também conhecida como a Lei das Águas, que estabelece a Política Nacional dos Recursos 
Hídricos e cria o Sistema Nacional de Gerenciamento de Recursos Hídricos (BRASIL, 1997). Porém, um problema enfrentado no Brasil é a não existência de uma regulamentação que trate definitivamente sobre a cobrança do uso, ficando a cargo dos comitês de bacias que, geralmente, enfrentam dificuldades para geri-las por falta de incentivos.

Alguns Comitês de Bacias Hidrográficas, como Bacia do Paraíba do Sul, que foi a pioneira em instituir a cobrança pelo uso da água, com início em 2003, possuem uma cobrança estabelecida na Deliberação CEIVAP $n^{\circ}$ 259/2018, que se baseia em um valor fixo no metro cúbico de água. Tais volumes são declarados pelos próprios usuários no momento do cadastro da outorga (CEIVAP, 2021). Esta ausência de controle incentiva uma maior captação de água por parte do usuário, não favorecendo a racionalização, o que fere um dos objetivos da Lei Federal n 9.433/1997.

Nem o Estado de Goiás e nem a bacia estudada possuem regulamentação para a cobrança do uso dos recursos hídricos.

\section{CONCLUSÃO}

Na bacia do Meia Ponte, a alta pressão hídrica sobre a região é motivadora para o investimento na prática de reúso. No entanto, um dos desafios para esse reúso é a sua produção a preços competitivos, o que tem ainda como um complicador a ausência de regulamentação para a cobrança do uso dos recursos hídricos no estado de Goiás e, em especial, na bacia em estudo.

Observa-se, ainda, que na Bacia Hidrográfica do Rio Meia Ponte há um baixo potencial instalado para a reutilização de água proveniente de ETE's, uma vez que existem pequenos índices de tratamento de esgotos nos municípios pertencentes à referida bacia, levando à produção de baixas vazões de efluente tratado.

Desta forma, observou-se no estudo que, em 10 das 12 ETE's analisadas, a oferta de água de reúso representa menos de $1 \%$ da demanda de água para irrigação. O município de Goiânia é o único que apresentou alto percentual de atendimento para a área e cultivo escolhido neste estudo. Para os municípios com baixas vazões de efluente, é plausível que se leve em conta a redução do raio de abrangência considerado para a irrigação, assim como a construção de sistemas de armazenamento de água, o que poderá garantir a reserva para os períodos de estiagem.

Além da necessidade de ampliação quanto à coleta e tratamento de esgoto, destaca-se, ainda, a importante tarefa de otimização das unidades atualmente em operação, de modo a alcançar níveis mais exigentes de qualidade, já que, tanto para o uso restrito como para o irrestrito, salientase que nenhuma das ETE's atende aos padrões recomendados pelo INTERÁGUAS (2018).

Por fim, recomenda-se a continuação dos estudos visando à avaliação do potencial do reúso para diferentes cultivos irrigados, bem como para melhor análise quanto ao raio de abrangência de atendimento compatível com o volume de oferta de água de reúso de cada ETE.

\section{REFERÊNCIAS}

ANA - Agência Nacional de Águas e Saneamento Básico. Atlas Irrigação: uso da água na agricultura irrigada/Agência Nacional de Águas. Brasília: ANA, 2017. 86p. ISBN 978-85-8210-051-6.

Catálogo de Metadados da ANA. Atlas Esgotos: Estações de Tratamento de Esgoto (2019) (Planilha). Brasil, 2019. Disponível em:

<https://metadados.snirh.gov.br/geonetwork/srv/api/rec ords/1d8cea87-3d7b-49ff-86b8-

966d96c9eb01/attachments/ATLAS_Esgotos_Tabela_ ETEs_2013.xlsx>. Acesso em: 29 jan. 2021.

ARAÚJO, B. M.; SANTOS, A. S. P.; DE SOUZA, F. P. Comparativo econômico entre o custo estimado do reúso do efluente de ETE para fins industriais não potáveis e o valor da água potável para a região sudeste do Brasil. Exatas \& Engenharias, v. 7, n. 17, p. 51-61, 2017.

; LIMA, M. A. M.; SOARES, S. R. A.; PERDIGÃO, C. A.; MELO, M. C. Avaliação do potencial de reúso de efluentes de ETE em áreas irrigadas da Bacia Hidrográfica Piancó-Piranhas-Açu com vistas à universalização. Augustus, Rio de Janeiro, v. 24, n. 49, p. 179-191, 2020.

BRASIL. Ministério do Meio Ambiente dos Recursos Hídricos e da Amazônia Legal. Lei no 9.433 de 08 de janeiro de 1997. Institui a Política Nacional de Recursos Hídricos, cria o Sistema Nacional de Gerenciamento de Recursos Hídricos, regulamenta o inciso XIX do art. 21 da Constituição Federal, e altera 0 art. $1^{\circ}$ da Lei $n^{\circ} \mathbf{8 . 0 0 1}$, de 13 de março de 1990, que modificou a Lei no 7.990, de 28 de dezembro de 1989. Brasília: Secretaria de Recursos Hídricos, 1997. 72p. 
Ministério do Desenvolvimento Regional.

Secretaria Nacional de Saneamento - SNS. Sistema Nacional de Informações sobre Saneamento: 25을 Diagnóstico dos Serviços de Água e Esgotos 2019. Brasília: SNS/MDR, 2020. 183p.

CEIVAP - Comitê de Integração da Bacia Hidrográfica do Rio Paraíba do Sul. Disponível em: <https://www.ceivap.org.br/cobranca-e-arrecadacao> Acesso em: 15 abr. 2021.

Deliberação CEIVAP no 259/2018 de 05 de abril de 2018. Dispõe sobre a atualização do Preço Público Unitário - PPU da metodologia da cobrança pelo uso dos recursos hídricos de domínio da União na Bacia Hidrográfica do rio Paraíba do Sul. Resende, RJ, 2018. 5p.

COELHO FILHO, J. A. P; CARDOSO, A.

T.; SOUZA, D. N.; VEIGA, A. M. Disponibilidade hídrica da Bacia Hidrográfica do Rio Meia Ponte - GO, pelos métodos Q7,10 e curva de permanência. In: Simpósio Brasileiro de Recursos Hídricos, Brasília, v. 21, p. 22-27, 2015.

FAO - Food and Agriculture Organization. Local Climate Estimator (New_LocClim). Disponível em: $<$ http://www.fao.org/land-water/land/landgovernance/land-resources-planningtoolbox/category/details/en/c/1032167/>.Acesso em: 28 jan. 2021.

FLORÊNCIO, L.; BASTOS, R.K.X.; AISSE, M.M. Tratamento e utilização de esgotos sanitários. Projeto PROSAB/ FINEP - CAIXA. Rio de Janeiro, ABES, 2006. 427 p. ISBN 85-7022-152-5.

GONÇALVES, R. F. (Coord.). Desinfecção de efluentes sanitários. Projeto PROSAB/ FINEP - CAIXA. Rio de Janeiro: Ed. ABES, RiMa, 2003. 438 p. ISBN 85-8655272-0.

GRANT, S.B.; SAPHORES, J. D.; FELDMAN, D. L.; HAMILTON, A. J. et al. Taking the "waste" out of "wastewater" for human water security and ecosystem sustainability. Science, v. 337, n. 6095, p. 681-686, 2012.

IMB - Instituto Mauro Borges de Estatística e Estudos Socioeconômicos. Goiás - Visão Geral. Julho, 2018. Disponível em:

<https://www.imb.go.gov.br/files/docs/publicacoes/goias -visao-geral/goias-visao-geral.pdf>. Acesso em: $07 \mathrm{fev}$. 2021.

INPE - Instituto Nacional de Pesquisas Espaciais.

Balanço Hídrico. INPE-13140-PRE/8399. São José dos Campos, 2005.
INTERÁGUAS - PROGRAMA DE

DESENVOLVIMENTO DO SETOR ÁGUAS

Elaboração de proposta de plano de ações para instituir uma política de reúso de efluente sanitário tratado no Brasil. Produto III - Critérios de qualidade de água, 2018. Disponível

em:<http://arquivos.ana.gov.br/interaguas/MCID_Reúso

_Produto3CriteriosdeQualidadedaAguadeReúso.pdf>.

Acesso em: 20 jan. 2021.

LEE, H.; TAN, T.P. Singapore's experience with reclaimed water: NEWater. International Journal of Water Resources Development, v. 32, n. 4, p. 611621, 2016.

LIBÂNIO, M. Fundamentos de qualidade e tratamento de água. 4. ed. Campinas-SP: Editora Átomo, 2016. 638p. ISBN 978-85-7670-271-9.

MAPBIOMAS. Projeto de Mapeamento Anual da Cobertura e Uso do Solo no Brasil. Coleção Anual 5.0 - Cerrado. Brasil, 2019. Disponível em: $<$ https://mapbiomas.org/colecoes-mapbiomas1 ?cama_set_language $=p t-B R>$. Acesso em: 30 jan. 2021.

MARCUZZO, F. F. N.; CARDOSO, M. R. D.; FARIA, T. G. Chuvas no cerrado da Região Centro-Oeste do Brasil: análise histórica e tendência futura. Ateliê Geográfico, Goiânia, v. 6 n. 2. p. 112-130, 2012.

MELO, M. C. SANTOS, A. S. P.; SANTOS, N. A. P.; ARAÚJO; B. M.; OLIVEIRA; J. R. S.; CAMPOS, A. R. Evaluation of potential use of domestic treated effluents for irrigation in areas subject to conflicts over water use in Paracatu River Basin. Caminhos de Geografia, Uberlândia, v. 21, n. 75, p. 52-63, 2020.

MINAS GERAIS. Deliberação Normativa do Conselho Estadual de Recursos Hídrico (CERH) n. 65.

Diretrizes, modalidades e procedimentos para 0 reúso direto de água não potável, proveniente de Estações de Tratamento de Esgotos Sanitários (ETE) de sistemas públicos e privados. Belo Horizonte, MG, 2020.

OCDE - Organização para a Cooperação e Desenvolvimento Econômico. Cobranças pelo uso de recursos hídricos no Brasil: Caminhos a seguir, OCDE, Paris, 2017. Disponível em: <http://dx.doi.org/10.1787/9789264288423-pt>. Acesso em: 31 jan. 2021.

RICHTER, L. A. Irrigação de pastagens. In: FONTANELI, R. S.; SANTOS, H. P. dos; FONTANELI, R. S. (Ed.). Forrageiras para integração lavourapecuária-floresta na região sul-brasileira. Cap. 17. 2. ed. Passo Fundo: Embrapa Trigo, 2012. 
ROBAINA, A. D. PEITER, M. X.; PARIZI, A. R. C.; SOARES, F. C.; GOMES, A. C. S. Modelagem do volume de reservatórios de irrigação para fins de outorga e planejamento agrícola. Ciência Rural, Santa Maria, v. 39, n. 9, p. 2482-2487, 2009.

SANTOS, A. S. P.; GONÇALVES, R. F.; MELO, M. C.; LIMA, M. A. M.; ARAÚJO, B. M. Uma análise crítica sobre os padrões de qualidade de água de uso e de reúso no Brasil. SUSTINERE, Rio de Janeiro, v. 8, n. 2, p. 437-462, 2020.

SEMAD - Secretaria de Estado de Meio Ambiente e Desenvolvimento Sustentável do Estado de Goiás. Planos de Recursos Hídricos das Unidades de Planejamento e Gestão de Recursos Hídricos do Estado de Goiás Afluentes ao Rio Paranaíba Diagnóstico UPGRH do Rio Meia Ponte. Diagnóstico (Produto 2), versão 2.0. Goiás, 2020.

SEMARH - Secretaria do Meio Ambiente e dos Recursos Hídricos. Manual Técnico de Outorga. $1^{\circ}$ Versão. Goiás, 2012.

Nota Técnica $n^{\circ}$ 01/2013-SRH. Detalhamento dos cálculos básicos para análise de processos de irrigação. Goiânia, GO, 2013.
Resolução nº 003, de 10 de abril de 2001.

Estabelece diretrizes para a formação e funcionamento dos Comitês de Bacias Hidrográficas do Estado de Goiás. Goiás, 2001.

SILVA JUNIOR, J. F.; HERNANDEZ, F. B. T.; SILVA, I. P. F.; REIS, L. S.; TEIXEIRA, A. H. C. Estabelecimento dos meses mais críticos para a agricultura irrigada a partir do estudo do balanço hídrico. BIOENG, Tupã, v.12, n. 2, p. 122-131, 2018.

SINAPI - Sistema Nacional de Pesquisa de Custos e Índices da Construção Civil. Preços e Insumos. Disponível em: <https://www.caixa.gov.br/poderpublico/modernizacao-gestao/sinapi/referenciasprecos-insumos/Paginas/default.aspx> Acesso em: 31 mar. 2021.

SLOAN, D. Water reuse foundation direct raw water blending in big spring; Proceedings of the Direct Potable Reuse Specialty Conference. Newport Beach, Califórnia, EUA, 2013. 